\title{
Políticas para o Ensino Superior no âmbito do projeto revolucionário bolivariano da Venezuela: aspectos históricos e conceituais
}

\author{
Maria Lucia Frizon Rizzotto* \\ Francis Mary Guimarães Nogueira ${ }^{* *}$
}

\section{Resumo}

Este estudo de caráter documental apresenta resultados de pesquisa que objetivou abordar aspectos históricos e conceituais que ajudam a compreender tanto a emergência do Projeto Revolucionário Bolivariano (PRB), como as razóes que levaram à criação da Universidade Bolivariana da Venezuela e da Missão Sucre, principal política do governo Chávez para o Ensino Superior. O recorte da pesquisa está circunscrito ao primeiro governo de Chávez, particularmente ao período compreendido entre 2003 e 2006. Buscou-se mostrar como o processo de formação em curso naquele país se articula com a implementação do PRB. Propóe-se também realizar análises acerca da concepçáo de formação subjacente à política de Ensino Superior. Neste artigo, concluiu-se que a apropriação de princípios liberais no processo educativo, dadas as contradições e a polarização que vive a sociedade venezuelana, pode não viabilizar a consecução do processo de transformação social em curso naquele país.

Palavras-chave: Ensino Superior - Venezuela. Universidade Bolivariana da Venezuela.

* Doutora em Saúde Coletiva pela Universidade Estadual de Campinas (Unicamp) e pós-doutorado em Educação pela Universidade Federal de Santa Catarina (UFSC). Professora associada da Unioeste - Campus de Cascavel. Professora do Curso de Enfermagem e do Mestrado em Educação.

** Doutora em Educação pela Universidade Estadual de Campinas (Unicamp). Professora associada da Unioeste - Campus de Cascavel. Professora do Curso de Pedagogia e do Mestrado em Educação. 


\section{Introduçáo}

Este trabalho de caráter documental e bibliográfico analisa aspectos históricos e conceituais da Venezuela que ajudam a compreender tanto a emergência do Projeto Revolucionário Bolivariano (PRB) e do Projeto Bolivariano de Educação (PBE), como as razóes que levaram à criação da Universidade Bolivariana da Venezuela (UBV) e da Missão Sucre, buscando evidenciar como a política e o processo de formaçáo no Ensino Superior daquele país se articulam com a implementação de um projeto socioeconômico, político e cultural distinto do existente até o final da década de 1990. Nesta direção, buscou-se elaborar análises acerca da concepçâo de formação presente nos documentos oficiais e em outros documentos da UBV, e em textos que expressam as políticas do governo para o Ensino Superior, sobretudo as políticas denominadas de Missóes, e no caso específico deste estudo, a Missão Sucre, criada em 2004, como parte das Missóes Educativas, que se realizam nas denominadas Aldeias Universitárias, e fecham o ciclo de formação da educaçáo escolar para aqueles setores da populaçáo que não tiveram a oportunidade de acesso ao Ensino Superior tradicional. $\mathrm{O}$ recorte da pesquisa está circunscrito ao período do primeiro governo de Hugo Chávez, mais particularmente entre 2003 e 2006, quando, por razóes históricas e conjunturais, ocorreram mudanças substanciais na direção das políticas econômica e social naquele país.

O processo venezuelano merece ser estudado tanto pelo que se diferencia do projeto neoliberal como pela influência que tem exercido em movimentos políticos e sociais na América Latina. As mudanças iniciadas na Venezuela não são frutos do acaso, mas em grande medida são resultado da implementação das reformas neoliberais colocadas em prática indistintamente nos vários paises latino-americanos a partir da década de 1980. Tais reformas trouxeram como consequência mediata o aumento da pobreza e das desigualdades sociais intrapaíses e entre os países da regiáo e os países centrais. As políticas neoliberais, se, de um lado, alcançaram seus objetivos em manter e aprofundar o processo de dependência com a transferência de riqueza para os países de capitalismo avançado, principalmente por meio de mecanismos como o pagamento dos juros e serviços da dívida externa, de outro, fizeram emergir movimentos contestatórios que colocaram em evidência as mazelas que essa transferência de riqueza provocou e provoca no conjunto da população dos países periféricos. 
No campo político, o resultado mais visível foi o surgimento de um nacionalismo democrático de base popular que assumiu como tarefa principal a solução dos graves problemas internos decorrentes da histórica exclusão de grandes contingentes da população dos benefícios da riqueza produzida. Ao mesmo tempo, os governantes de alguns países, com destaque para a Venezuela, compreenderam que a solução dos problemas domésticos depende da unidade e da integração dos países da região, visando à formação de um bloco econômico e político mais consistente, com capacidade de romper com a atual forma subordinada e dependente de inserção dos países da região na dinâmica capitalista mundial, e quiçá contribuir para a construção de outro projeto de sociedade, distinto do projeto burguês. A Revolução Bolivariana da Venezuela, como projeto político-econômico, se insere neste contexto histórico e tem suas raízes anteriormente à eleição de Hugo Chávez para a Presidência da República, em dezembro de 1998.

\section{Antecedentes históricos do atual processo político venezuelano}

Merece destaque na história da Venezuela o processo de independência do país do jugo espanhol, que foi resultado de intensas lutas internas e de uma guerra civil que durou dez anos (1811-1821), cujos objetivos, já naquele momento, não se limitavam às atuais fronteiras da Venezuela, mas expandiam-se para outras colônias espanholas com o intuito de construir uma grande pátria livre, a Gran Colombia, hoje constituída basicamente pelos limites geográficos da Venezuela, Colômbia, Equador e Panamá. Simón Bolívar, principal figura histórica da independência, já entendia que a liberdade de seu país, a Venezuela, só se consolidaria se todos os países do continente fossem livres e houvesse uma unidade e integração entre eles.

Com a ascensão ao poder, Chávez recolocou na cena política do país figuras como Simón Bolívar e Simón Rodríguez, recuperando princípios, visóes de mundo, de homem, de educação e de sociedade, o que também agora não se restringe à nação venezuelana, mas pretende que envolva outros povos da América Latina. Esses objetivos, identificados na defesa da soberania nacional e na integração latino-americana, ajudam a dar conformação ao atual projeto econômico, político e cultural da Venezuela. As raízes desse projeto podem ser buscadas no campo político, mas é na esfera econômica que se encontram as explicaçóes mais consistentes. 
A economia venezuelana, desde o século XVIII, caracterizou-se como extrativista. Primeiro produzindo e exportando cacau; no século XIX, se expandiu para a produção de café, e, a partir do início do século XX, o petróleo se tornou o principal produto de exportação. Desde 1925 até 1986, quando caíram os preços do petróleo pela primeira vez, o crescimento econômico do país foi quase constante (BERGQUIST apud ELLNER, 2003). A partir de 1958, com a instauração da democracia liberal, a Venezuela "[...] comenzó un proyecto de 40 años diseñado para construir una serie de instituciones y establecer prácticas para cambiar la economía de extracción de origen hispánico y reemplazar la débil infraestructura institucional heredada del pasado" (LOMBARDI, 2003, p. 14).

Nos anos 1970, os altos recursos do petróleo beneficiaram, não da mesma forma, todas as classes sociais, por meio de subsídios, baixos impostos, controle de preços, serviços públicos como educação e saúde, e um generoso sistema de seguridade social. Ao mesmo tempo, a economia petroleira "[...] debilitó a la oligarquía, al campesinado y a la clase obrera, y les impidió construir sus propias organizaciones políticas [...]” (ELLNER, 2003, p. 21). Além disso, os recursos do petróleo fizeram emergir uma burocracia improdutiva, que, mesmo com mudanças no governo, permanecem com forte influência nas instituições públicas daquele país, mantendo as mesmas práticas de corrupção, o que evidencia a dificuldade de se derrotar a estrutura do Estado burguês, independentemente da via que se escolha para promover a transformação social.

A bonança experimentada nas décadas de 1960 e 1970 foi o ponto culminante de um projeto que associava democracia burguesa, nacionalismo petroleiro e desenvolvimento econômico, iniciado em 1958, com a fundação da mais longa democracia liberal da América Latina. Tal projeto, denominado Pacto del Punto Fijo, se deu a partir de acordo realizado entre os dois principais partidos políticos daquela época, a Ação Democrática (AD) e o partido cristáo Copei (NORDEN, 2003). No entanto, a estabilidade política se revelou frágil diante da determinação econômica. Poucos anos depois de iniciada a crise econômica dos anos 1980, os indicadores sociais do país se deterioraram, levando ao fim do Pacto del Punto Fijo e colocando em xeque o próprio modelo de democracia, considerada exemplo para a América Latina.

Se durante a década de 1970 houve uma melhora substantiva nas condiçóes de vida da população venezuelana, uma vez que em 1978 apenas 
$10 \%$ da população eram considerados pobres, a partir da década de 1980 , com o início da crise econômica, os cortes nos gastos sociais e nos salários dos trabalhadores levaram ao aumento inevitável da pobreza. "Entre 1984 a 1995, el porcentaje de la población pobre aumentó de 36\% a 66\%, mientras el sector en pobreza extrema aumentó más del triple, de $11 \%$ a 36\%" (EVANS apud ROBERTS, 2003, p. 80). O progressivo empobrecimento e o aumento exponencial das desigualdades sociais levaram a uma crescente polarização da sociedade, fazendo reaparecer a divisão de classes que estava entorpecida pela distribuição de renda das décadas anteriores.

Outro fato que merece destaque se deu em fevereiro de 1989, quando o então Presidente Carlos Andrés Pérez, logo após assumir o cargo, contradizendo o seu discurso eleitoral, anunciou a negociação do primeiro acordo do país com o Fundo Monetário Internacional (FMI). Em reação às medidas de ajuste impostas pelo acordo e como sintoma da degradação das condiçóes de vida, teve início em Caracas, em 27 de fevereiro, um levante popular que se estendeu para várias cidades do país, conhecido como Caracazo. Este levante espontâneo e de massa agudizou as tensóes sociais e durou até 19 de março, quando o exército foi chamado para controlar a revolta, uma vez que a polícia não havia conseguido pôr fim às manifestaçóes. O Caracazo e os distúrbios ocorridos ao longo da década de 1990 mostraram a fragilidade da tese da excepcionalidade venezuelana, que via esse país como diferente de seus vizinhos latino-americanos, quer pela maturidade política, quer pelo fato de ser grande produtor de petróleo e ter conseguido instituir uma melhor repartição da renda nacional (ELLNER, 2003).

Com as inúmeras manifestaçóes de protesto e de reivindicação que ocorreram após o Caracazo, foi ficando evidente a incapacidade das organizaçóes sindicais de defenderem os interesses dos trabalhadores informais, que já eram maioria no país, bem como de os partidos políticos representarem as camadas populares. Nesse vazio de representação, emergiram novas forças sociais, entre elas o grupo cívico-militar denominado Movimento Bolivariano Revolucionário-200 (MBR-200), ao qual Hugo Chávez se vinculava e que articulou o fracassado golpe cívico-militar de 1992, que o levou à prisão, bem como a outros militares rebeldes por dois anos, de 1992 a 1994 (HELLINGER, 2003).

Mesmo preso, Chávez se tornou símbolo da possibilidade de mudança para o povo venezuelano que, em 1998, agora pela via democrática, o 
elegeu Presidente da República. Desde sua ascensão ao poder, o governo de Chávez vem procurando implementar um projeto econômico, político e cultural que tem como objetivo central "refundar a república" a partir da ampliação da participação do povo nas decisóes políticas, por meio de diversos mecanismos constitucionais como o referendo, a consulta popular e os conselhos comunais, e pela incorporação massiva da população nas Missóes Sociais em diversas áreas sociais.

Apesar da debilidade e desarticulação inicial da oposição, todas as questôes, por menores que possam parecer, se transformam em polêmica nacional e alimentam o debate acirrado entre as forças políticas em disputa. De todos os enfrentamentos que ocorreram entre o governo e a oposição, um resultou em importantes mudanças nos rumos da política interna do país. Trata-se da greve ou paro petrolero, que ocorreu entre dezembro de 2002 e fevereiro de 2003. Depois de quase três meses de greve, o governo conseguiu pôr fim à paralisação e assumir o controle da política petroleira do país, que até então, apesar da mudança de governo, continuava nas mãos dos antigos dirigentes da Petróleos de Venezuela S.A. (PDVSA), os quais estavam articulados com as corporaçóes internacionais de extração e refino do petróleo. A partir desse momento, o governo entendeu que teria que atuar de forma distinta nos campos econômico, político e social, se quisesse efetivar o projeto de país com o qual se elegeu. $\mathrm{Na}$ área social, passou a implementar uma série de políticas de caráter massivo, denominadas de missóes, financiadas com recursos vindos diretamente da PDVSA. Entre as açóes voltadas para a consecução do Projeto Revolucionário Bolivariano (PRB), no que se refere ao Ensino Superior, está a criação da Universidade Bolivariana da Venezuela (UBV) e da Missão Sucre.

\section{A formação em nível superior na Venezuela: a UBV e a Missão Sucre}

Com o Decreto Presidencial n. 2.517 de 18 de julho de 2003, foi criada a UBV, tendo por objetivo constituir-se em uma "[...] alternativa al sistema educativo tradicional, al tiempo que da un vuelco a la vinculación de la Universidad con la realidad nacional y latinoamericana” (UNIVERSIDAD BOLIVARIANA DE VENEZUELA, 2007, p. 1). Com a criação dessa universidade e com a Missão Sucre, o governo pretendeu dar uma 
nova direção ao Ensino Superior público no país, no sentido de formar profissionais vinculados às comunidades, comprometidos com o projeto de "refundação do Estado venezuelano" e com a reconstrução da "Venezuela bolivariana”. Para isso, seria necessário formar um novo homem, com traços humanísticos, comprometido e solidário, cuja formação deveria se pautar em um "[...] nuevo modelo educativo capaz de generar conocimiento pertinente, relevante y creativo para realizar aportes significativos a la vida nacional" (UNIVERSIDAD BOLIVARIANA DE VENEZUELA, 2003, p. 1).

Estes pressupostos orientaram e orientam a criação de cursos/ programas de graduação em nível central, nas sedes da UBV e nas aldeias universitárias, como são denominados os locais onde se desenvolvem os cursos/programas da Missão Sucre. As aldeias universitárias estão presentes em todos os municípios do país, caracterizando um processo de municipalização e universalização do Ensino Superior. Inicialmente, foram criados dez cursos/programas na sede da UBV, em Caracas. Em nosso entendimento, todos os cursos/programas criados tinham como objetivo imediato formar profissionais que pudessem contribuir para a implementação do $\mathrm{PRB}$, respondendo a problemas críticos como os de habitação e saúde (cursos de Arquitetura, Gestão em Saúde Pública e Medicina Integral Comunitária); para dar respostas às necessidades específicas do novo Estado em construção (cursos de Estudos Jurídicos e Estudos Políticos); para contribuir com a implementação do projeto de desenvolvimento endógeno ${ }^{1}$ (cursos de Gestão Ambiental, Gestão Social do Desenvolvimento Local e Agroecologia); para fazer frente à nova dinâmica de participação protagônica ${ }^{2}$ (cursos de Informação para a Gestão Social e Comunicação Social) ou ainda para promover mudanças na formação dos professores e, consequentemente, dos alunos com o Programa Nacional de Formação de Educadores.

Os cursos/programas implantados na UBV e na Missão Sucre não se reproduzem igualmente em todas as sedes e aldeias universitárias do país. Pelo próprio entendimento de desenvolvimento endógeno que prioriza as potencialidades e necessidades das comunidades locais, a definição desses cursos/ programas depende do planejamento e das demandas locais, daí a existência da política de municipalização da educação, em todos os níveis de ensino, o que não significa a transferência da responsabilidade de financiamento, nem mesmo a ausência de uma articulação e centralização da política. 
O entendimento do papel do Ensino Superior no processo de transformação econômica, política e cultural da sociedade venezuelana é expresso por um dirigente da UBV nos seguintes termos:

Construir el Poder Popular en nuestra naciente República Bolivariana pasa por la refundación de todas las políticas públicas sobre otro propósito; en particular la Educación Superior, la cual constituye un instrumento que posibilita el cambio de mentalidad necesario para rescatar el valor intrínseco y social de todos y cada uno de los venezolanos. (RUIZ, 2006, p. 1).

Nesta perspectiva, a refundação da república requer uma nova concepção de política social, que rompa com o instituído até então e ajude a edificar as bases de um novo Estado Democrático e Social de Direito e de Justiça. Nesse sentido, a orientação geral para a elaboração dos desenhos curriculares deve "[...] vincular el programa con el desarrollo integral del país y por tanto a desarrollar la identidad del egresado como profesional altamente cualificado, éticamente responsable y ciudadano comprometido con la consolidación de nuestra democracia”.

Tal pressuposto compóe as Bases, Criterios y Pautas para el diseño curricular de los Programas de Formación de la $U B V$, portanto, são princípios que orientam a estruturação de todos os cursos/programas da instituição (REPÚBLICA BOLIVARIANA DE VENEZUELA, 2006, p. 3).

A orientação dos cursos/programas se vincula ao projeto nacional que se pretende construir naquele país, o qual "[...] requiere una apuesta a un proyecto educativo pensado para el mediano y largo plazo. Hay que pensar que los republicanos del mañana serán los que deben estar armados ética, técnica y humanísticamente para transformar su destino y el de la república" (REPÚBLICA BOLIVARIANA DE VENEZUELA, 2006, p. 7). Nesse sentido, a formação a ser realizada não se pretende neutra, ao contrário, a articulação do processo formativo ao novo projeto de sociedade é concebida como elemento fundamental para operar as transformaçóes no campo social e econômico. Era "[...] imposible pensar en iniciar un nuevo proyecto de país con el modelo educativo de nuestras universidades tradicionales", portanto, as instituições de ensino "[...] tienen la gran misión 
de preparar a la generación de nuevos ciudadanos y nuevas ciudadanas, que encarnen el espíritu republicano, contenido en el proyecto de país, con alto contenido ético y de compromiso social" (REPÚBLICA BOLIVARIANA DE VENEZUELA, 2006, p. 4).

Com este entendimento do papel da formação escolar no processo de transformação da realidade social, "[...] se pretende el desarrollo y la aplicación del proyecto bolivariano en los contenidos y formas en consonancia con las transformaciones sociales y económicas que se producen en la vida de nuestra sociedad" (REPÚBLICA BOLIVARIANA DE VENEZUELA, 2006, p. 4). Assim se expressa a política de Educação Superior, que visa a formar profissionais comprometidos com o projeto revolucionário em curso, traduzida na criação da $\mathrm{UBV}^{3}$ e na Missão Sucre.

\section{Pressupostos teórico-metodológicos que dão sustentação ao processo de formaçáo na Venezuela}

Antes de apresentar os principais elementos teóricos presentes no projeto educacional bolivariano, cabe destacar que a educação escolar não se constitui em um projeto político e cultural descolado da história e baseado em princípios universais, se constitui, sim, como expressão das relaçóes sociais que emergem do modo como se produz e reproduz a vida material e espiritual em uma sociedade concreta.

Com base neste pressuposto e na observação empírica, é possível afirmar que o PEB revela a possibilidade concreta de universalizar a cobertura escolar em todos os níveis de ensino, concretizando, assim, o direito de oportunidades iguais para todos. No entanto, diante das contradiçóes da própria sociedade venezuelana e da correlação de forças em nível nacional e internacional, o PEB incorporou parte de uma concepção de educação defendida pela UNESCO, como veremos na sequência do texto, que tem como princípio uma educação escolar baseada no ensino de hábitos e procedimentos que visam ao desenvolvimento de atributos que favoreçam a construção e manutenção da coesão social e, consequentemente, do modo de produção vigente. A hegemonia do pensamento neoliberal no campo educacional a partir dos anos de 1990 e a inexistência concreta de outro projeto teórico para a educação em condições de se contrapor a este impossibilitaram à Venezuela, dadas as condiçôes históricas, de nos primeiros 
anos de implementação do $\mathrm{PRB}$, construir uma alternativa pedagógica capaz de superar a proposta da UNESCO.

Ao fazer a crítica ao modelo de formação vigente, que teria elitizado o ensino em todos os níveis, o projeto educacional bolivariano incorpora os elementos centrais presentes na proposta de formação da UNESCO: "El modelo educativo que se pretende impulsar se plantea el desarrollo de estrategias que privilegien los cuatro pilares de un nuevo tipo de educación: aprender a conocer, aprender a hacer, aprender a vivir juntos y aprender a ser" (VENEZUELA, 2005b, p. 4).

Este mesmo entendimento está presente em outros documentos oficiais que tratam da formação docente, como o Programa Nacional de Formación de Educadores y Educadoras:

La integralidad y la progresividad articulan de manera coherente y continua los ejes del aprender a convivir, saber y hacer que se dan a través de los niveles educativos correspondientes a cada período de vida, para formar como síntesis al ser social como el(la) nuevo(a) republicano(a) bolivariano(a). (VENEZUELA, 2004, p. 13).

Contudo, ao buscar romper com o processo de formação instituído nas universidades do país, que favorece "[...] el desarrollo de creencias e ideologías que configuran, desde la visión exclusiva de lo individual, modelos culturales de dominación [...]", os documentos apontam a necessidade da "[...] reconciliación entre las ideas y la realidad", o que implica "[...] desarrollar la aptitud para relacionar el pensamiento y la acción, permitiendo a la sociedad venezolana intervenir en su propia historia y, así, transfomarla" (VENEZUELA, 2005b, p. 25).

As orientações pedagógicas explicitadas anteriormente têm origem em organismos internacionais e foram apresentadas de forma mais acabada no Relatório da Comissão Internacional sobre Educação para o século XXI, da UNESCO, denominado "Educação: um Tesouro a Descobrir", coordenado por Jacques Delors. Neste relatório, que visa a “[...] traçar orientaçôes válidas, tanto em nível nacional como mundial”, a educação aparece com uma perspectiva redentora, responsável pelo desenvolvimento pessoal e social e mediadora das relaçóes entre indivíduos, grupos e nações, visando à “[...] 
construção dos ideais da paz, da liberdade e da justiça social” (DELORS, 2000, p. 11).

Não cabe aqui uma análise do conteúdo do relatório da UNESCO, o que já foi feito por muitos estudiosos da educação no Brasil ${ }^{4}$, apenas destacar como essas orientaçóes foram incorporadas nos programas de formação em nível superior, na Venezuela, traduzidas em documentos e, consequentemente, no projeto bolivariano de educação, tentando evidenciar contradições presentes neste complexo histórico.

Considerando que na Venezuela a opção pela democracia, como via de transformação da sociedade, foi a escolha da maioria da população ao eleger Hugo Chávez como Presidente da República, em 1998 e em 2006, cabe uma análise da forma como a democracia é concebida no Projeto Revolucionário Bolivariano, uma vez que esta categoria é também destacada na proposta educacional da UNESCO.

A Constituição da República Bolivariana de Venezuela estabelece a democracia participativa e protagônica como pilar da nova Carta, incorporando mecanismos mais diretos de intervenção popular "[...] a fin de garantizar la coexistencia de ambas as formas de democracia, representativa y participativa, y de estimular el ejercicio de esta última por parte de las organizaciones sociales más que por los partidos politicos tradicionales" (GARCÍA-GUADILLA, 2003, p. 232).

Em relação à democracia participativa, esta tem sido interpretada como o "[...] perfeccionamiento de la democracia representativa mediante mecanismos de participación tales como el referendo, las asambleas de participación o la rendición de cuentas. Ello significa que una democracia participativa será también representativa" (GARCÍA-GADILLA, 2003, p. 232).

Já o protagonismo do povo, segundo a nova Constituição, se dará na formação, execução e controle da gestão pública.

Conforme expresso no Artigo $70^{\circ}$ da Constituição, tanto a participação como o protagonismo podem se dar no campo político, por meio da eleição de cargos públicos, referendo, consulta popular, revogação de mandato ${ }^{5}$, iniciativas legislativa, constitucional e constituinte, e assembléia de cidadãos e cidadâs ${ }^{6}$; e, no campo social e econômico, por meio das instâncias de atenção ao cidadão, autogestão, cogestão, cooperativas, caixas de poupança, empresas comunitárias ou outras formas associativas (VENEZUELA, 2000). 
Para Álvarez (2003, p. 197), essas inovações, introduzidas na Constituição, não se configuram como uma mera modernização da democracia representativa, "[...] el poder constituyente persiguió la trasformación revolucionaria de la democracia formal en una forma original de gobiernos que ha otorgado al pueblo un papel "protagónico".

Sobre esta questão, no Relatório Delors, a partir de uma análise da complexidade do mundo moderno, dos inúmeros problemas enfrentados pela humanidade que vão desde as guerras até questões ecológicas, culturais e étnicas, estabelece-se uma relação direta entre democracia, entendida como "participação da vida em comunidade", e o "aprender a viver juntos”, um dos pilares da UNESCO. O relator parte da pergunta: como viver juntos nesta aldeia global, se não somos capazes de viver em comunidades "naturais" como a vizinhança, a aldeia, a cidade, a região ou a nação?

Com esta preocupação, no referido relatório, é dedicado um capítulo para discutir a relação entre coesão social e democracia, no qual se afirma que a democracia corresponde a um "[...] sistema político que procura assegurar, por meio do contrato social, a compatibilidade entre liberdades individuais e uma organização comum da sociedade", que neste momento estaria sendo ameaçada pela desorganização das sociedades e pela ruptura dos laços sociais. Portanto, caberia à educação, que deve ocorrer ao "longo de toda a vida do cidadão", não só preparar cada indivíduo para o convívio e exercício dos seus direitos e deveres, mas "[...] construir uma sociedade civil ativa que [...] permita cada um assumir sua parte de responsabilidade como cidadâo a serviço de um destino autenticamente solidário" (DELORS, 2000, p. 53).

A partir destes elementos, no relatório, afirma-se que "aprender a viver juntos” deve ser um processo que se inicia no nível local e está intimamente relacionado com a decisão de cada um, ou seja, uma decisão de caráter subjetivo. No PRB, a participação do povo, por meio dos diferentes mecanismos de participação, com destaque para os Conselhos Comunais ${ }^{7}$, se constitui no eixo central da democracia protagônica que garante o desenvolvimento tanto individual como coletivo dos cidadãos historicamente excluídos.

Em relação à perspectiva localista, na apresentação do relatório, Delors salienta que, para "aprender a viver juntos", os seres humanos teriam que superar algumas tensóes existentes. Entre ela, estaria a tensão entre o nível 
global e o local, ou seja, como tornar-se cidadão do mundo sem perder as raízes, sem abandonar a cultura própria. Outra tensão estaria entre o universal e o singular, ou como compatibilizar a cultura mundializada, preservando a cultura local e as tradições.

A questão local, em documento analisado, parece expressar entendimento distinto do enunciado acima:

[...] la estrategia de la municipalización de la educación superior, enfatizando en su desarrollo la redimensión de lo regional, lo local teniendo como referencia las necesidades educativas y potencialidades reales de la población, sin desvincularla de su contexto asegurando la pertinencia social y la preservación del arraigo cultural. (VENEZUELA, 2005b, p. 4).

Observe-se que não apenas se assume o nível local como lócus privilegiado para a definição do processo de formação, na medida em que este precisa considerar as necessidades e potencialidades da comunidade e ter "pertinência social', ou seja, ser relevante socialmente, contribuir para o desenvolvimento individual e da comunidade, para o "fortalecimiento del poder local" e incorporação "de los estudiantes a los procesos socio-productivo del pais", mas entende-se que é a partir deste espaço que se devem buscar a formação geral, a soberania nacional e a integração latino-americana, tendo como horizonte a construção de uma nova realidade regional, como também pode-se observar na citação que segue:

La Municipalización valora la búsqueda de la totalidad abierta del ser humano, a través de la formación integral de estudiantes y docentes [...] y revitalizando la integración desde una perspectiva histórica, rescatando nuestras raíces latinoamericanas [...] (VENEZUELA, 2005b, p. 4-5).

A educação ao longo da vida é outro tema presente tanto no relatório da UNESCO como nos programas de formação na Venezuela. Sobre isso, nos documentos analisados, há o entendimento de que a Educação Superior precisa dar conta, não só da formação individual dos alunos, mas também do desenvolvimento das comunidades nas quais estiver inserida. Para isso, seria necessária a oferta de "[...] oportunidades formativas a lo 
largo de la vida, con autonomía responsable e independiente de intereses ajenos a la cultura académica integral, flexible y abierta en su organización académica y programas" que respeitassem as necessidades e potencialidades da comunidade (VENEZUELA, 2005b, p. 5).

No relatório da UNESCO, a educaçáo ao longo da vida aparece na perspectiva de ocupar o tempo ocioso ou como exigência democrática de ter que aprender a viver juntos ou, ainda, como "condiçáo para um domínio mais perfeito dos ritmos e dos tempos da pessoa humana" (DELORS, 2000, p. 104). Ou ainda como estratégia para superar "a tensão entre a competiçấo e o cuidado com a igualdade de oportunidades" e "a tensão entre o extraordinário desenvolvimento dos conhecimentos e a capacidade de assimilação do homem", em que a educaçáo ao longo da vida deveria "[...] dar a cada ser humano os meios de poder realizar todas as suas oportunidades" e ao mesmo tempo "[...] conciliar a competição que estimula, a cooperação que reforça e a solidariedade que une" (DELORS, 2000, p. 15).

O projeto educacional bolivariano incorpora esses elementos na medida em que atribui responsabilidade à universidade e às missóes educativas em relação ao desenvolvimento das comunidades onde se insere.

La presente propuesta curricular está basada en los principios de formación integral que conjuga lo humanístico y lo ético con lo científico-tecnológico. Caracterizado por: la responsabilidad con lo público, el ejercicio del pensamiento crítico, la flexibilidad e integración y el diálogo de saberes, la calidad con equidad, así como el principio de educación a lo largo de toda la vida (educación permanente). (VENEZUELA, 2005a, p. 3).

Assim, a comunidade acadêmica da UBV e da Missão Sucre comprometida com o novo projeto de país, na visão do governo, deve se reconhecer como "[...] parte de la Universidad y de su comunidad, y en ella $y$ desde ella contribuyan a su transformación y potencien su función pública" (VENEZUELA, 2005b, p. 4).

Para cumprir com essas atribuiçôes e estabelecer estes vínculos, é fundamental que a formação acadêmica não "[...] desvincúlese de lo vivencial como experiencia de aprendizaje y como espacio para la producción 
de conocimiento y saberes y de inserción social, desde donde se reproduzca la solidaridad y se construya ciudadanía" (VENEZUELA, 2005b, p. 4).

Nessa mesma direção, o projeto educacional bolivariano faz uma vinculação entre educação e trabalho conforme explicitado no art. 102 da Constituição Federal, que afirma ser a educação um serviço público com a finalidade de:

[...] desarrollar el potencial creativo de cada ser humano y el pleno ejercicio de su personalidad en una sociedad democrática basada en la valoración ética del trabajo y en la participación activa, consciente y solidaria en los procesos de transformación social consustanciados con los valores de la identidad nacional, y con una visión latinoamericana y universal. (VENEZUELA, 2000, p. 36).

Identifica-se também, no projeto educacional bolivariano, tanto o tema da educação como formação ao longo da vida como o foco na experiência pessoal, na vivência, na aprendizagem centrada no aluno, bem como a discussão do desenvolvimento de competências e da flexibilização curricular, conforme pode ser observado na citação que segue.

La municipalización debe [...] dar cuenta de las tendencias actuales de la educación: privilegio a la Educación como continuum, a lo largo de la vida, el eje del proceso es el aprendizaje, la Educación de adultos es una prioridad, el aprendizaje está centrado en el estudiante, en la práctica, lo vivencial, lo problematizador y promueve el desarrollo de competencias, permitiendo que se propicien espacios de participación para la toma de decisiones y se posibilite la construcción de un currículo que responda a la sociedad. (VENEZUELA, 2005b, p. 6-7).

Como pode ser observado nas citaçóes anteriores, extraídas de documentos da UBV, o que em grande medida se repete em outros documentos da área educacional do governo da Venezuela, determinadas orientaçóes contidas no relatório da UNESCO foram incorporadas e 
apresentadas como diretrizes educacionais e estratégias pedagógicas na proposta de formação do projeto educacional bolivariano. A assimilação das propostas da UNESCO, nesse projeto e nas propostas de formação em nível superior, também estão presentes na própria Constituição. Depois de definir os direitos dos cidadãos e as atribuiçóes do Estado em relação à educação em todos os níveis, está explícito no art. 30 que "[...] a tal fin, el Estado realizará una inversión prioritaria, de conformidad con las recomendaciones de la Organización de las Naciones Unidas [...." (VENEZUELA, 2000, p. 37).

Note-se que o projeto educacional venezuelano náo ficou isento da influência do pensamento predominante em termos de concepção pedagógica e de formação, e expressa contradiçóes de uma sociedade que visa a garantir a ampliação de direitos, incorporando categorias e princípios liberais.

Com base nos elementos apresentados acima e em outros enunciados presentes em documentos da área da educação do governo Chávez, bem como na literatura que dá sustentação teórica ao projeto educacional bolivariano, ${ }^{8}$ é possível apreender os elementos centrais que ajudam a compor a concepção de formação desse projeto e das práticas pedagógicas assumidas como estratégia para a emancipação cultural, política e econômica do país.

Em linha geral, a educação escolar é vista como possibilidade de promover o desenvolvimento, tanto em nível individual, na medida em que tem como finalidade "[...] desarrollar el potencial creativo de cada ser humano y el pleno ejercicio de su personalidad en una sociedad democrática [...]" (VENEZUELA, 2000, p. 36), como em nível coletivo, sendo "[...] un medio para lograr la justicia, la igualdad y la integración social." (VENEZUELA, 2006b, p. 7).

Portanto, a escola passa a ter a responsabilidade de formar um novo homem, que deve estar "a serviço da refundação da república", ocupando-se de conhecimentos que tenham sentido para a vida, partam das experiências e visem a formar um cidadão republicano, patriótico, solidário e com profundo sentido humanitário, preparado para compartilhar a vida social e construir a integração latino-americana. Por isso, a educação escolar deve se ocupar de conhecimentos próprios e demandaria novas estratégias pedagógicas que libertem e não domestiquem, que descolonizem o pensamento, favorecendo, assim, a emancipação do pensamento, a independência e a soberania. 
Toda educación es reflejo de la interioridad y de la clase de relaciones que sus miembros han desarrollado en el tiempo. Gran parte de las relaciones sociales están vinculadas directa o indirectamente con el proceso educativo formal e informal y contribuye a mantener y reproducir la organización y condiciones del sistema. (DEL GROSSO, 1951 apud EGLEE, 2006, p. 14).

Segundo Casanova (2005), o projeto educacional em curso na Venezuela expressa a emergência de um novo "contrato educativo", que se contrapóe ao projeto neoliberal da década de 1990 e caracteriza-se por uma volta aos ideais históricos do republicanismo, do racionalismo laico e do espírito iluminista da Revolução Francesa. As mudanças políticas que acompanharam a subida de Chávez ao poder permitiram, no campo educacional, o ressurgimento de correntes de pensamento educativo que estavam subsumidas durante a hegemonia neoliberal. Junto com estas correntes, é recolocado no centro da cena política o tema da reconstrução da escola pública e a educação como espaço privilegiado de sociabilidade e de realização dos princípios pendentes de igualdade, fraternidade e igualdade.

Essa análise de Casanova pode ser confirmada na leitura de autores incorporados ao projeto educacional bolivariano que defendem o caráter popular e de massa para a educação, bem como a responsabilidade do Estado em garanti-la, buscando efetivar as promessas liberais não cumpridas desde a criação da república naquele país. Isto é, a universalização, a gratuidade e a laicidade da educação.

La educación de masas, sin hacer distinción, de acuerdo con la posición social del individuo, de la fortuna o de la raza, tiende a capacitar al pueblo todo para intervenir en la dirección de sus destinos y para servir mejor, por la adquisición de habilidades y conocimientos que le coloca en pie de igualdad con los otros miembros de la comunidad. La educación democrática o educación de masas aspira a dar igualdad de oportunidades para todos; por ello es gratuita y obligatoria y debe crear instituciones que favorezcan a los menos posibilitados económicamente para ascender en la escala de la cultura. (FIGUEROA, 1951, p. 27). 
A filosofia da Escola Nova, teorizada por John Dewey nas décadas de 1910 e 1920, penetrou também em países como a Venezuela como ideal de igualdade de oportunidades escolares para todos. No entanto, pela confirmação histórica da ausência de acesso do conjunto da população à educação escolar na América Latina, esta promessa liberal não poderia se concretizar em uma Venezuela que, desde a década de 1920 passou a ser controlada por uma burguesia rentista que viveu, direta ou indiretamente, dos recursos produzidos pela economia petroleira. Como este ideal democrático, começam a se concretizar, no governo de Hugo Chávez, estes princípios traduzidos na democracia participativa e protagônica, que se constituem também em fundamentos da proposta de formação na UBV e na Missão Sucre.

A incorporação, no projeto educacional bolivariano, de pressupostos que carregam elementos de uma racionalidade vinculada ao ideário liberal e que, por princípio, parecem divergir do que se pretende instituir como fundamento de uma nova sociabilidade, pode não se constituir em uma trava para o processo de transformação social em curso na Venezuela, uma vez que outras concepçóes e práticas também são constitutivas desse processo social. Além disso, o caráter autônomo e hegemônico da educação escolar, de acordo com a orientação filosófica da Escola Nova, parece não se manifestar em toda a sua plenitude na Venezuela.

A nova sociabilidade que busca romper com a lógica de acumulação vigente está expressa na Constituição de 1999 e define mudanças na função do Estado, da economia e da educação. O novo Estado deve se orientar pelo tripé do direito, da democracia e da justiça social; a economia, mediante a intervenção direta do Estado e da criação de mecanismos de participação dos cidadãos, deve transitar para um novo modelo produtivo de caráter social; e a educação, nesse contexto, assume um papel central no processo de inclusão e de acesso ao conhecimento, e de construção de um novo homem comprometido com a transformação em curso. Assim, a penetração dos pressupostos da UNESCO no projeto educacional venezuelano, em face das contradiçóes existentes e dos mecanismos postos em prática pelo governo Chávez, parece que não tem significado uma adequação imediata e mecânica da formação na perspectiva de perpetuar as relaçóes sociais capitalistas. 


\section{Consideraçóes finais}

Com base na análise empírica realizada, é possível afirmar que a criaçãa da UBV e da Missão Sucre, como projeto de formação para o Ensino Superior, compóe uma resposta concreta do Estado venezuelano, que vem contestando as bases das práticas econômicas, políticas e sociais do neoliberalismo e promovendo um nacionalismo democrático de base popular.

Este processo de confrontos da política externa do Governo Chávez, particularmente contra o imperialismo estadunidense, associado à política doméstica que se contrapóe à burguesia rentista e às corporaçóes multinacionais, vem indicando que cabe à educação escolar formar um novo homem que zele por e persiga a construção da democracia participativa com o protagonismo do povo historicamente excluído. Nesse contexto, a educação assume um papel central no projeto revolucionário bolivariano, uma vez que se articula de forma orgânica com as mudanças econômicas, políticas e culturais em andamento.

Pelos dados históricos de como se deu o processo de luta para a implantação da república no século XIX e de outros antecedentes do Governo Chávez, bem como a concepção de formação expressa nos documentos oficiais, é possível identificar, no referido projeto, o objetivo de desenvolver o potencial criativo de cada ser humano, em âmbito individual e coletivo, sendo um meio para conseguir a justiça, a igualdade e a integração social.

A concepção de formação presente nos documentos analisados não nos parece, pelo menos no período estudado, incoerente com o Projeto Revolucionário Bolivariano, que constrói as bases da refundação da República, idealizada por Simón Bolívar e retomada no projeto de educação de Hugo Chávez, que objetiva La Suprema Felicidad Social, resultado da mudança de comportamento dos indivíduos.

Considerando que a formação escolar se constitui em uma política de Estado, fincada em uma sociedade contraditória, que se expressa em uma forte polarização política entre a burguesia local, vinculada diretamente aos interesses dos Estados Unidos da América, e a grande maioria da população, é possível afirmar, provisoriamente, no caso concreto da Venezuela, que os princípios liberais presentes nos documentos analisados podem não inviabilizar o processo revolucionário bolivariano em curso, já que a educação 
não tem um caráter autônomo e hegemônico em relação às bases materiais em que se assenta a sociedade.

A crítica à incorporação dos pressupostos da UNESCO, associada ao avanço do Projeto Revolucionário Bolivariano, particularmente no que se refere ao projeto econômico, pode resultar na superaçáo dessa concepçáo de educação e na elaboração de uma nova concepção que contribua para a emancipação humana. Além disso, as mudanças no caráter da propriedade, inscritas na Constituição em vigor desde 1999, e a reiteração em documentos oficiais da necessidade de participação política do povo nas decisóes relevantes do país, por meio da atuação nos Conselhos Comunais e a partir de 2009 com a junção de vários Conselhos nas denominadas Comunas, além dos diversos tipos de referendos, buscam dar continuidade e aprofundar o chamado Socialismo do Século XXI. Essas ações vão respaldando politicamente os atos legais de estatização e nacionalização de setores estratégicos da economia.

Por isso, o resultado da forma particular de apropriação de determinados pressupostos teóricos, no projeto educacional da Venezuela atual, e as mudanças operadas depois do recorte definido por esta pesquisa nos instigam a continuar essa investigação, tanto pelos desdobramentos no campo da formação stricto sensu como no campo da política educacional, que pode sofrer alteraçóes substanciais em sua concepção, dado o movimento concreto histórico da economia e da política venezuelana, bem como a partir da própria crítica e/ou autocrítica teórica que este processo tem imposto, particularmente, aos intelectuais venezuelanos que pensam o projeto revolucionário e, em geral, aos intelectuais críticos da América Latina que estão desafiados a interpretar as mudanças que ocorrem na Venezuela e em outros países da região.

\section{Notas}

1 Enfoque de desenvolvimento que busca criar e consolidar uma estrutura produtiva progressivamente autossuficiente, que permita atender às necessidades de desenvolvimento social e humano das comunidades em intercâmbio solidário com outras comunidades, a nação e outros países.

2 O protagonismo é essencialmente a participação política que visa a submeter os governantes ao mandato popular revogatório e proporcionar 
o autogoverno do povo mediante diversas formas constitucionais de participação.

3 A UBV é a instituição responsável pela certificação dos estudantes dos cursos/programas de nível superior, quer sejam ofertados nas sedes da UBV, quer nas aldeias universitárias, por meio da Missão Sucre.

4 Entre os autores que realizaram a crítica, citamos Evangelista e Shiroma, (2006), Campos e Shiroma (2002), e Nagel (2007).

5 Todos os cargos eletivos podem ser revogados, uma vez transcorrido metade do mandato. Para ocorrer o referendo, é necessário ter a assinatura de pelo menos $20 \%$ dos eleitores, que não pode ser feita mais de uma vez para o mesmo ocupante do cargo. Será revogado o mandato, se igual ou maior número de votantes que elegeu o representante votar pela sua revogação. Para haver a possibilidade de revogação, devem participar do processo eleitoral pelo menos $25 \%$ dos inscritos para votar.

6 As “[...] asambleas de ciudadanos y ciudadanas cuyas decisiones serán de carácter vinculante, confiere al pueblo la potestad de imponer su mandato al gobernante" (ÁLVAREZ, 2003, p. 198).

7 Conselhos Comunais são instâncias de participação popular, previstas na Constituição, com poder para propor e gerir projetos sociais financiados com recursos públicos.

8 Em documentos oficiais do governo e em discursos de ministros de Estado, faz-se referência a autores que escreveram sobre educação, como Simón Rodríguez, José Martí, Luis Beltrán Prieto Figueroa e José Del Grosso. Além disso, o Ministério de Educação e Desporte tem reproduzido e distribuiu gratuitamente para os professores da rede pública uma série de livros desses autores, indicando a adoção de seus pressupostos na política e na prática educacional do PEB.

\section{Referências}

ÁLVAREZ, Á. E. La reforma del Estado antes y después de Chávez. In: ELLNER, S.; HELLINGER, D. (Ed.). La politica venezolana en la época de Chávez: clases, polarización y conflicto. Caracas: Consejo de Investigación de la Universidad de Oriente/Nueva Sociedad, 2003. 
CAMPOS, R. F.; SHIROMA, E. O. O resgate da Escola Nova pelas reformas educacionais contemporâneas. Revista Brasileira de Estudos Pedagógicos, Brasília, v. 80, n. 196, p. 483-493, 2002.

CASANOVA, R. Venezuela después del liberalismo: de los consensos de la reforma de los ańos noventa a un nuevo contrato educativo? In: CENDES. Venezuela visión plural: una mirada desde el Cendes. Caracas,VE: bid\&co.editor/ CENDES-UCV, 2005. Tomo I.

CONSTITUCIÓN de la República Bolivariana de Venezuela. Gaceta Oficial, Venezuela, extraordinario n. 5.453, 24 mar. 2000.

DELORS, J. et al. (Coord.). Educação: um tesouro a descobrir: relatório para a UNESCO da Comissão Internacional sobre Educação para o Século XXI. Tradução José Carlos Eufrázio. São Paulo: Brasília, DF: Cortez/UNESCO, 2000.

EGLEE, M. R. El conocimiento y la reflexión de lo individual y lo colectivo como herramienta para la educación superior bolivariana. Caracas, 2006. Mimeografado.

ELLNER, S. El sindicalismo frente al desafío del chavismo. In: ELLNER, S.; HELLINGER, D. (Ed.). La política venezolana en la época de Chávez: clases, polarización y conflicto. Caracas: Consejo de Investigación de la Universidad de Oriente/Nueva Sociedad, 2003.

; HELLINGER, D. (Ed.). La política venezolana en la época de Chávez: clases, polarización y conflicto. Caracas: Consejo de Investigación de la Universidad de Oriente/Nueva Sociedad, 2003.

EVANGELISTA, Olinda; SHIROMA, E. O. Educação para alívio da pobreza: novo tópico na agenda global. Revista de Educação, Campinas, v. 20, p. 43-54, 2006.

FIGUEROA, L. B. P. De una educación de castas a una educación de masas. La Habana: Lex, 1951.

GARCÍA-GUADILLA, M. P. Sociedad civil: institucionalización, fragmentación, autonomía. In: ELLNER, S.; HELLINGER, D. (Ed.) La politica venezolana en la época de Chávez: clases, polarización y conflicto. Caracas: Consejo de Investigación de la Universidad de Oriente/Nueva Sociedad, 2003. 
HELLINGER, D. Visión política general: la caída del puntofijismo y el surgimiento del chavismo. In: ELLNER, S.; HELLINGER, D. (Ed.) La politica venezolana en la época de Chávez: clases, polarización y conflicto. Caracas: Consejo de Investigación de la Universidad de Oriente/Nueva Sociedad, 2003.

LOMBARDI, J. V. El permanente dilema de Venezuela: antecedentes de las transformaciones chavistas. In: ELLNER, S.; HELLINGER, D. (Ed.). La política venezolana en la época de Chávez: clases, polarización y conflicto. Caracas: Consejo de Investigación de la Universidad de Oriente/Nueva Sociedad, 2003. Prólogo.

NAGEL, L. H. Educação e desenvolvimento na pós-modernidade: algumas reflexóes. In: NOGUEIRA, F. M. G.; RIZZOTTO, M. L. F. (Org.) Políticas sociais e desenvolvimento: América Latina e Brasil. São Paulo: Xamã, 2007. v. 1, p.19-43.

NORDEN, D. L. La democracia en uniforme: Chávez y las fuerzas armadas. In: ELLNER, S.; HELLINGER, D. (Ed.). La politica venezolana en la época de Chávez: clases, polarización y conflicto. Caracas: Consejo de Investigación de la Universidad de Oriente/Nueva Sociedad, 2003.

REPÚBLICA BOLIVARIANA DE VENEZUELA. Ministerio de Educación Superior. Universidad Bolivariana de Venezuela. Programa de formación de grado: Gestión en Salud Pública. Caracas, 2006.

ROBERTS, K. Polarización social y resurgimiento del populismo en Venezuela. In: ELLNER, S.; HELLINGER, D. (Ed.). La politica venezolana en la época de Chávez: clases, polarización y conflicto. Caracas: Consejo de Investigación de la Universidad de Oriente/Nueva Sociedad, 2003.

RUIZ, E. M. El conocimiento y la reflexión de lo individual y lo colectivo como herramienta para la educación superior bolivariana. Caracas, 2006. Mimeografado.

UNIVERSIDAD BOLIVARIANA DE VENEZUELA. Bases, criterios y pautas para el diseño curricular de los Programas de Formación de la UBV. Caracas: [s.n.], 2003. 


\section{UNIVERSIDAD BOLIVARIANA DE VENEZUELA. República} Bolivariana de Venezuela. Caracas: UBV, 2007. Disponível em: <http:// www.ubv.edu.ve.>. Acesso em: 15 mar. 2007.

VENEZUELA. Constitución (2000). Constitución de la República Bolivariana de Venezuela: promulgada en 24 de marzo de 2000. Gaceta Oficial Extraordinaria: n. 5.453, 2000.

VENEZUELA. Ministerio de Comunicación e Información. Las misiones bolivarianas. Caracas, 2006a. (Colección Temas de Hoy).

VENEZUELA. Ministerio de Educación y Deporte. La educación bolivariana. Caracas, 2004. (Educación como continuo humano, v.1, n. 6). VENEZUELA. Ministerio de Educación Superior. Programa Nacional para la Formación del Médico Integral Comunitario de la República Bolivariana de Venezuela. Caracas, 2005a.

VENEZUELA. Ministerio de Educación Superior. Universidad Bolivariana de Venezuela. Programa de Formación de Grado: Gestión en Salud Pública. Caracas, 2005b.

VENEZUELA. Programa Nacional de Formación de Educadores y Educadoras - PNFED. Caracas: Coordinación de Ediciones de Publicaciones/ UBV, 2006b. 


\section{Policies for higher Education in the realm of Venezuela's Revolutionary Bolivarian Project: historic and conceptual factors}

\section{Abstract}

This study of primary documents presents the results of research that sought to consider historical and conceptual factors that help understand both the emergency of the Bolivarian Revolutionary Project, as well as the reasons that led to the creation of the Universidade Bolivariana da Venezuela and of the Missão Sucre, the main higher education policy of the Chavez government. The research focuses on the first Chavez administration, particularly the period from 2003-2006. It sought to show how the educational process in that country is related with the implementation of the Bolivar Project. The study also analyzes the conception of education subjacent to the higher education policies. The article concludes that the appropriation of liberal principles in the educational process, given the contradictions and polarization experienced by Venezuelan society, cannot make impede achievement of social transformation underway in that country.

Key words: Higher education - Venezuela. Universidade Bolivariana da Venezuela.

\section{Políticas para la Educación superior en el ámbito del Proyecto Revolucionario Bolivariano de Venezuela: aspectos históricos $y$ conceptuales}

\section{Resumen}

El texto que presentamos es un estudio de carácter documental y es resultado de una investigación cuyo objetivo fue abordar los aspectos históricos y conceptuales que ayudan a comprender tanto el surgimiento del Proyecto Revolucionario Bolivariano (PRB) como también las razones en que se creó la Universidad Bolivariana de Venezuela y la Misión de Sucre, principal política del Gobierno de Chávez, en especial en el período comprendido entre 2003 y 2006. Se buscó mostrar como el proceso de formación en curso en aquel país se articula con la implementación del PRB. También se realiza un análisis acerca de la concepción de formación subyacente a la política de Educación Superior. En este artículo se concluye, que la apropiación de principios liberales en el proceso educativo, a partir de las contradicciones y la polarización que vive la sociedad venezolana, puede no viabilizar la consecución del proceso de transformación social que está en curso en ese país.

Palabras clave: Educación Superior Venezuela. Universidad Bolivariana de Venezuela. 


\section{Maria Lucia Frizon Rizzotto}

Rua Visconde do Rio Branco, 1861 ap. 32

CEP: 85802-190

Cascavel - PR

E-mail: frizon@terra.com.br

\section{Francis Mary Guimaráes Nogueira}

Rua Carlos de Carvalho, n. 4066 ap. 101 - Centro

CEP: 858010-080

E-mail: guimanog@terra.com.br

Recebido em: 20/4/2009

Aprovado em: 30/7/2009 